\title{
Consumer Perception and Preference of Drinking Water Sources
}

\author{
Seyed Ali Sajjadi ${ }^{1}$, Vali Alipour ${ }^{2}$, Mohammad Matlabi ${ }^{3}$, Hamed Biglari ${ }^{4}$
}

\begin{abstract}
${ }^{1}$ Ph.D. of Environmental Health, Associate Professor, Department of Environmental Health Engineering, School of Public Health, \& Social Determinants of Health Research Centre, Gonabad University of Medical Sciences, Gonabad, Iran

${ }^{2}$ Ph.D. of Environmental Health, Assistant Professor, Department of Environmental Health Engineering, School of Public Health, Research Center for Social Determinants in Health Promotion, Hormozgan University of Medical Sciences, Bandar Abbas, Iran

${ }^{3}$ Ph.D. of Health Education, Assistant Professor, Department of Health Education \& Promotion, School of Public Health, Gonabad University of Medical Sciences, Gonabad, Iran

${ }^{4}$ MSc. of Environmental Health, Senior Lecturer, Department of Environmental Health Engineering, School of Public Health, Social Development \& Health Promotion Research Center, Gonabad University of Medical Sciences, Gonabad, Iran
\end{abstract}

\section{Type of article: Original}

\begin{abstract}
Introduction: Understanding consumer perception of drinking water can contribute to improvements in water management and consumer satisfaction. The aim of this study was to assess the consumer perception of tap water quality and other drinking water sources in Gonabad as a small semiarid city.

Methods: This study was performed in autumn and winter 2013. For collection data a researcher-made a questionnaire consisting of nine questions, based on demographic information prepared. Questions were asked for participants to provide information regarding household drinking water usage and patterns, opinion about tap water safety, taste and reasons for purchasing bottled water. For statistical analysis, analysis of variance (ANOVA) using SPSS version 16 was applied in this study.

Results: Results showed that demographic variables had a significant relationship with consumer satisfaction ( $p$ $<0.05$ ). Office employees, women and poor families had the most satisfaction from tap water quality. Peoples' preferences for tap water, commercial softener, domestic softener, ghanat (a type of underground cistern) and bottled water were $27.8,19,27.8,40.4$ and $3.5 \%$ respectively. Dissatisfaction from production of foam, unsuitable taste, unacceptable appearance and other problems in tap water was 11.1, 95.6, 27.8 and $0.4 \%$ respectively. Consumer reasons for using domestic water softeners are: suitable taste $(80 \%)$, easy availability (71\%), economical (56\%) and low health side effects (34\%).

Conclusion: According to these results it was clear that each consumer group, based on self-condition, prefers using a specific drinking water source.
\end{abstract}

Keywords: Consumer perception, Tap water, Water quality, Water source, drinking water

\section{Introduction}

Consumer perception of drinking water quality has existed for thousands of years. In the past, people have believed that good drinking water should be cold, nutritive, transparent and potable, but their perception of biological and chemical water quality was not remarkable (1). Nowadays, since the link between drinking water quality and human health is evidently identified, the WHO has been emphasizing that "all people, whatever their stage of development or social and economic conditions, have the right to have access to a suitable supply of safe drinking water" (2).

\section{Corresponding author:}

Hamed Biglari, Department of Environmental Health Engineering, School of Public Health, Social Development \& Health Promotion Research Center, Gonabad University of Medical Sciences, Gonabad, Iran.

Tel: +98.5157225027 Fax: +98.5157223814, Email: Biglari.h@gmu.ac.ir

Received: June 10, 2016, Accepted: September 18, 2016, Published: November 2016

iThenticate screening: August 01, 2016, English editing: October 24, 2016, Quality control: November 04, 2016

(C) 2016 The Authors. This is an open access article under the terms of the Creative Commons Attribution-NonCommercialNoDerivs License, which permits use and distribution in any medium, provided the original work is properly cited, the use is non-commercial and no modifications or adaptations are made. 
Although presence of a public water distribution network is often an indicator of suitable water supply in a developing country, it should not be expected that the piped water quality is always adequate for human consumption (3), apparently, the composition of (drinking) water varies accordingly with hydro-geological conditions of locations. Water normally contains high or low levels of gases, minerals and natural organic matter, therefore, either ground water or surface water has never been chemically pure $\mathrm{H}_{2} \mathrm{O}$ (1). This composition is related to natural processes (weathering and soil erosion) and human activities (discharging sanitary and industrial waste waters to receiving waters). In dry and semi dry areas, due to extreme temperature changes during different times, natural processes such as soil erosion and rock weathering lead to changes in water quality. Therefore, in these areas, contents of dissolved solids, as an index for salty water, increases more than its standard amount (4). Therefore, in these areas tap water quality is not favorable as drinking water and people, in these areas, prefer using other water sources, for example artificially-produced demineralized water (5), bottled water or ghanat cistern water. In this condition, consumers may use one of them based on their perception of accessible drinking water sources and economic condition. According to previous studies, if any of these water sources fail to have the maximum acceptable concentration of inorganic and organic substances, consumers could be faced with many health problems (1). For example, the use of an unhealthy and contaminated cistern or ghanat causes increasing diseases such as cholera, diarrhea, salmonellosis and typhoid. Giardiasis has been the cause of mortality of more than 2 million people worldwide the majority of whom were children younger than 5 years old (6). The most prevalent contaminants of cisterns and ghanats are heavy metals and polluted runoffs from agricultural activities and precipitation (7). Today, due to probable contamination of natural water sources the use of bottled water is increasing. Obtained results from analyzing bottled water have shown that the amount of nitrite, nitrate, total coliform and fecal coliform is in the acceptable line, but most of these waters are classified in hard water. Although bottled water has no taste, the quantity of calcium, manganese and other minerals is high and this character is favorable only for human suffering from the essential minerals defection. A study of peoples' satisfaction of bottled water in Kerman city has shown that the majority of people were pleased with bottled water, but according to their opinions, bottled water was costly (8). Because of cost and the lack of easy access to bottled water, one of the emergency water sources is artificially-produced demineralized water. This system is used for removing or decreasing unfavorable materials existing in the drinking water (9). Over the last three decades, desalination has become a wide common practiced technique in drinking water supply. A study in 2005 reported that there were more than 11,000 desalination plants worldwide, which produced in total, more than six billion gallons of desalinated water each day. (1) Many countries in the Persian Gulf region, Central Asia and North Africa rely almost entirely on desalination plants for supplying their drinking water (10-12). Indeed, it is a proven technology to produce freshwater in the Middle East $(13,14)$. Despite the high energy demands, capital costs and environmental concerns, desalination appears to be an alternative for low rainfall countries such as Australia (15). Although previously many studies had been conducted on drinking water quality, a lot of them have compared the quality of natural water sources with new treated water sources. In Gonabad city this study focused on two research questions. First, what is the consumer perception of tap water and other sources? Secondly, was there a relationship between peoples' perception of tap water quality and the use of other water sources that one consumes?

\section{Material and Methods}

This study, with the aim of assessing the relationship between consumer perception of tap water and consumption of other drinking water sources, was performed in autumn and winter 2013 in Gonabad city. Gonabad is located in the south of Khorasan Razavi province at latitudes $34^{\circ} 3^{\prime}-34^{\circ} 54^{\prime} \mathrm{N}$, and longitudes $46^{\circ} 57^{\prime}-59^{\circ} 27^{\prime} \mathrm{E}$, and has an area of approximately $9584 \mathrm{~km}^{2}$. The population is approximately 74,000. Drinking water sources in Gonabad are 14 wells, 18 cisterns and 4 ghanats. Also, there are three companies active in supplying soft and fresh water. For this reason, a researcher-made questionnaire, based on demographic information (age, gender, marital status, job, monthly income, literacy level, history of residency in Gonabad) was prepared. For analyzing demographic characteristics of Gonabad people in different areas, 400 questionnaires were distributed among 400 participants according to stratified method. Questions were asked for participants to provide information regarding household drinking water usage and patterns, opinion about tap water safety, and taste and other reasons for purchasing bottled water. The questionnaire consisted of nine questions which were written for the purpose of this study. Inclusion criteria were having a minimum age of 15 years old and having a minimum 3 months residency in Gonabad city. According to an expert's view in Gonabad city, this questionnaire had acceptable reliability and validity. For statistical analysis, analysis of variance (ANOVA) using SPSS version 16 (SPSS Inc. Chicago, Illinois, USA) was applied in this study. Also $\mathrm{p}<0.05$ was considered for significance level. 


\section{Results}

The results revealed that demographic characteristics of consumer perception of tap water quality such as resident history, gender, literacy level, job and monthly income had an effect on the satisfaction score $(p<0.05)($ Table 1$)$. Female satisfaction was higher than male. Also literate persons with office jobs were more satisfied than others. But there was an indirect relationship between satisfaction amount and monthly income, and participants who had income lower than 5,000,000 Rials had more satisfaction than others $(\mathrm{p}<0.05)$. Results obtained from the amount of peoples' preference in available drinking water sources showed that Gonabad peoples' preferences in ghanat and cistern, tap water, domestic water softeners, commercial water softeners and bottled water were $40.4 \%, 27.8 \%$, $27.8 \%, 19 \%$ and 3.5\% respectively. Results obtained from the amount of people who preferred available drinking water sources showed that Gonabad peoples' preferences in ghanat and cistern, tap water, domestic water softeners, commercial water softeners and bottled water were $40.4 \%, 27.8 \%, 27.8 \%, 19 \%$ and $3.5 \%$ respectively. Problems of tap water quality, according to consumer perception based on peoples' views, found that the main reasons for the poor quality of tap water were unsuitable taste $(60.7 \%)$, unacceptable appearance $(27.8 \%)$, production of foam $(11.1 \%)$ and other reasons were $0.4 \%$. These results were confirmed by chemical analysis results of Gonabad drinking water. A 2007 study by Keramati et al. showed that the chemical analysis on drinking water such as electrical conductivity (EC), total dissolved solid (TDS), sodium $\left(\mathrm{Na}^{+}\right)$, bicarbonate $\left(\mathrm{HCO}_{3}{ }^{-}\right)$and chloride $\left(\mathrm{Cl}^{-}\right)$in Gonabad tap water were higher than the national standard, but its calcium $\left(\mathrm{Ca}^{2+}\right)$ and $\mathrm{Magnesium}\left(\mathrm{Mg}^{+2}\right)$ concentrations were less than national standards (13). Therefore, it is clear that sodium salines, including $\mathrm{NaCl}$ and $\mathrm{NaHCO}_{3}$ are dominant compositions in drinking water and existence of these compositions will give taste to drinking water. The obtained results based on peoples' perception of t domestic water softeners were clear that the notable number of consumers $(12.8 \%)$ preference to use of domestic water softener. Consumer reasons for using domestic water softeners are: suitable taste (80\%), easily available (71\%), economical (56\%) and low health side effects $(34 \%)$. For solutions to the problems and reaching to an integrated management, consumers suggested some management options such as design of separation water supply for water drinking purposes (59.9\%), fresh water preparation for total consumers $(17.9 \%)$ and an offer of a free domestic water softener to a family $(17.4 \%)$.

Table 1. The relationship between demographic characteristics of Gonabad people and their satisfaction score

\begin{tabular}{|c|c|c|c|c|c|c|}
\hline \multirow{2}{*}{\multicolumn{2}{|c|}{ Demographic characteristics }} & \multirow{2}{*}{\multicolumn{5}{|c|}{ Satisfaction score; $\mathrm{n}(\%)$}} \\
\hline & & & & & & \\
\hline \multirow{4}{*}{$\begin{array}{l}\text { Resident history in Gonabad } \\
\text { city (year) }\end{array}$} & $<20$ & $\begin{array}{l}\text { Very high } \\
15(12.1) \\
\end{array}$ & \begin{tabular}{|l|} 
Moderate \\
$71(57.3)$ \\
\end{tabular} & $\begin{array}{l}\text { Low } \\
38(30.6) \\
\end{array}$ & $\begin{array}{l}\begin{array}{l}\text { Total } \\
\text { number }\end{array} \\
124(100)\end{array}$ & $\begin{array}{l}\mathrm{p}- \\
\text { value } \\
<0.05\end{array}$ \\
\hline & $20-39$ & & & & & \\
\hline & $40-59$ & $7(12.5)$ & $30(53.6)$ & $19(33.9)$ & $56(100)$ & \\
\hline & $\geq 60$ & $3(21.4)$ & $8(57.1)$ & $3(21.40)$ & $14(100)$ & \\
\hline \multirow[t]{2}{*}{ Gender } & Female & $\begin{array}{l}70 \\
(71.40)\end{array}$ & $27(27.6)$ & $1(1.55)$ & $98(100)$ & \multirow[t]{2}{*}{$<0.05$} \\
\hline & Male & $20(9)$ & $\begin{array}{l}122 \\
(54.7)\end{array}$ & $\begin{array}{l}81 \\
(36.30)\end{array}$ & $223(100)$ & \\
\hline \multirow[t]{3}{*}{ Literacy level } & Illiteracy & $4(50)$ & $4(50)$ & $0(0.00)$ & $8(100)$ & \multirow[t]{3}{*}{$<0.05$} \\
\hline & $\begin{array}{l}\text { Up to high school } \\
\text { diploma }\end{array}$ & $\begin{array}{l}122 \\
(73.10)\end{array}$ & $\begin{array}{l}44 \\
(26.30)\end{array}$ & $1(0.60)$ & $167(100)$ & \\
\hline & $\begin{array}{l}\text { University } \\
\text { Graduation }\end{array}$ & $\begin{array}{l}68 \\
(71.57)\end{array}$ & $\begin{array}{l}26 \\
(27.36)\end{array}$ & $1(1.07)$ & $95(100)$ & \\
\hline \multirow[t]{3}{*}{ Job } & Farmer & $2(40)$ & $3(60)$ & $0(0.00)$ & $5(100)$ & \multirow[t]{3}{*}{$<0.05$} \\
\hline & Office employee & $\begin{array}{l}36 \\
(78.30)\end{array}$ & $\begin{array}{l}10 \\
(21.70)\end{array}$ & $0(0.00)$ & $46(100)$ & \\
\hline & Self-employed & $\begin{array}{l}124 \\
(70.5)\end{array}$ & $51(29)$ & $1(0.60)$ & $176(100)$ & \\
\hline \multirow[t]{4}{*}{ Monthly income (I.R.R.) } & $<5,000,000$ & $\begin{array}{l}39 \\
(76.50)\end{array}$ & $\begin{array}{l}12 \\
(23.50)\end{array}$ & $0(0.00)$ & $51(100)$ & \multirow[t]{4}{*}{$<0.05$} \\
\hline & $\begin{array}{l}5,000,000- \\
10,000,000\end{array}$ & $1(0.80)$ & $34(27)$ & $91(72.2)$ & $126(100)$ & \\
\hline & $\begin{array}{l}10,000,000- \\
20,000,000\end{array}$ & $\begin{array}{l}30 \\
(65.20)\end{array}$ & $\begin{array}{l}16 \\
(34.80)\end{array}$ & $0(0.00)$ & $46(100)$ & \\
\hline & $>20,000,000$ & $2(50)$ & $2(50)$ & $0(0.00)$ & $4(100)$ & \\
\hline
\end{tabular}




\section{Discussion}

As a result of this study, we found persons who had more residents' history, were more satisfied than others. These results were in agreement with the results of Doria and Parkin et al. (15). Because older respondents with a longer history of residency have observed relative improvements from society and the government on various issues over time, their viewpoints may be more positive than younger consumers $(11,14)$. Younger consumers appeared to be more dissatisfied with tap water (11) since their perception was that it seemed a rather risky (11) or susceptible water supply facility (6). Our results showed that females and persons with university education were satisfied with tap water. It may be due to education effects on consumers' perception of chemicals compounds in drinking water. Educated people are more expected to consider that there is a lesser risk of tap water contamination (7). Therefore, there was a positive link between education and perception of chemical pollution of potable water (9). Moreover, education seems to influence choosing mass media. Although, another study reported an insignificant association between education and individual concerns on risks of tap water (10). Besides educational levels, gender difference, such as a sense of vulnerability sensed by women, gender structure, visions and beliefs are other major factors affecting perception on drinking water quality (11). Because of high awareness about water quality and low income for purchasing of processed water, it seems that office employees and poor families had more satisfaction from tap water quality respectively. Based on obtained results from previous studies it has been found that higher income would create opportunities to purchase alternatives to tap water (12). With regard to peoples' perception of tap water quality, using other alternatives to tap water is necessary. A study in Canada found that mean tap water consumption was around $38 \%$, while filtered water and bottled water were respectively $40 \%$ and $22 \%$ of the total water consumption. The study also claimed that socio-demographic and health acuity were the most substantial factors in choosing filtered and/or bottled water compared to tap water; our results approved that peoples' preference for bottled water is negligible, which was confirmed by results of other research (15). Compared to our results, few studies reported that it was because of fear from tap water contamination, many Latino parents gave their children bottled water for drinking, as well as using bottled water to prepare infant formula (14, 16). Also, in regions of Nogales, Arizona, 85\% and 50\% of people used bottled water for drinking and cooking respectively (17). According to the previous studies, highly educated individuals have less preference for consumption of bottled water. Possibly, this echoes the fact that educated individuals have better access to scientific information related to drinking water quality $(14,18,19)$. Scientific enquiries revealed that despite marketing bottled water as a safer alternative to tap water, in the regions with poor water quality, there were concerns about potential chemical leaks from bottles during a long storage period, particularly under unfavorable conditions (high temperature, sunlight, etc.) which may contaminate the water. As a result, bottled water is not necessarily safer than tap water (20). It is notable that all bottled water is not mineral water. "Mineral waters are those waters that contain the minimum $1000 \mathrm{mg} / \mathrm{kg} \mathrm{salt}$ or $250 \mathrm{mg}$ of free Carbonic Anhydride per $1 \mathrm{~kg}$. Mineral waters flow directly from natural springs or by digging up underground layers" (21). A study in the United States claimed that 55\% of respondents found tap water chemicals unpleasant (15). Another study initially reported that $57 \%$ of participants stated that "not knowing the composition of water was one of the main causes for concern or dissatisfaction" (11). Taste and odor rely on cognitive body performance which according to their importance varies between individuals and cultures. In some cultures, water taste is considered more important than odor or appearance, probably because the taste could reveal water chemicals at lower levels than the other senses (11). Another problem of tap water in Gonabad city was the production of foam that so far, no source has been cited for it. According to studies performed in this field, plants and algae inhabiting watersheds produce many organic compounds of which, some $\neg$ have surfactant properties. Natural surfactants include carboxylic fatty acids derived from plant lipids and lignins from wood which have foaming properties. These compounds, existing in water, contribute to a large variety of soluble organic material collectively referred to as dissolved organic carbon (DOC) (22-26). Although based on the opinions of the people of Gonabad, the idea of using softeners has many advantages, according to previous studies, also this technology has disadvantages. Most water softeners on a large and industrial scale operate correctly for the purpose of water treatment or hardness removal, but on a small and domestic scale they operate incorrectly or even release dangerous materials to drinking water. The most common domestic water softeners have a plastic container and a filter composed with active carbon and an ion exchange resins, located inside of this plastic container. $\neg$ This filter should be washed or exchanged after a certain time. More information about the act of washing and exchanging filters, saturation time, suitable washing solutions, and method of using them is required. After a certain time they are saturated and should be exchanged and understanding exchange time requires skill and experience. Therefore, even if these filters act correctly, after saturation they should be exchanged. If they are not exchanged within a suitable time, many materials and bacteria adsorbed on filter will enter the drinking water again $(1,27,28)$. The Management solutions suggested by people for improvement of drinking water quality is that each consumer based on self-condition, prefers using a specific drinking water source, although the water source may be polluted or unhealthy. 


\section{Conclusions}

The results showed that demographic variables had a significant relationship with consumer satisfaction $(\mathrm{p}<0.05)$. Office employees, women and poor families had the most satisfaction with tap water quality. People had specific preferences to tap water, commercial softener, domestic softener, ghanat cistern and bottled water. The importance of this study is that its information can be used in consumer views for selecting a source of suitable quality of water resource and satisfaction with the supply service. So, it is suggested that for each consumer, based on self-condition, prefers using a specific drinking water source, the standards should be designed based on the protection of human health and satisfaction of consumers. Investigation of additional research for surveying consumer's perception and preference on drinking water sources available in a dry region, based on this methodology, could be an interesting avenue for future research in this field.

\section{Acknowledgments:}

The authors are grateful for the financial support of this project by the health research deputy of Gonabad University of Medical Sciences and technical support during this study with code of 20/92.

\section{Conflict of Interest:}

There is no conflict of interest to be declared.

\section{Authors' contributions:}

Sajjadi was statistical consultant and text editor of the study. Biglari was designer, performer and leader of the study. Alipour and Matlabi were advisors of experiment, sampling and analyzing. Biglari also conducted the study.

\section{References:}

1) Kozisek F. Health risks from drinking demineralised water. Nutrients in Drinking Water. 2005; 148-63.

2) Biglari H, Chavoshani A, Javan N, Mahvi AH. Geochemical study of groundwater conditions with special emphasis on fluoride concentration, Iran. Desalination and Water Treatment. 2016; 57(47): 1-8. doi: 10.1080/19443994.2015.1133324.

3) Mirzabeygi M, Naji M, Yousefi N, Shams M, Biglari H, Mahvi AH. Evaluation of corrosion and scaling tendency indices in water distribution system: a case study of Torbat Heydariye, Iran. Desalination and Water Treatment. 2016; 57(54): 1-9. doi: 10.1080/19443994.2016.1162206.

4) Gelca R, Hayhoe K, Scott-Fleming I, Crow C, Dawson D, Patiño R. Climate-water quality relationships in Texas reservoirs. Hydrological Processes. 2016; 30(1): 12-29. doi: 10.1002/hyp.10545.

5) Mohammadi Sh, Mohammadi M, Tavakkoli K, Zamani E, Mohadeth Z, Mogtahedi F, et al. Effects of Different Doses of Simvastatin on Lead-Induced Kidney Damage in Balb/C Male Mice. Pharmaceutical Sciences. 2015; 20(4): 157-162.

6) Po M, Kaercher JD, Nancarrow BE. Literature review of factors influencing public perceptions of water reuse: Citeseer. 2003. PMID: 7973368.

7) Neil N, Malmfors T, Slovic P. Intuitive toxicology: Expert and lay judgments of chemical risks. Toxicol Pathol. 1994; 22(2): 198-201. PMID: 7973368.

8) Rajabizadeh A, Afsarinejad MR. Evaluation of Knowledge and Attitude of Kerman Residents about the Usage of Bottled Water for Drinking and Cooking Purposes. Kerman medical sciences university. 2004; 11(4): 243-50.

9) Auslander BA, Langlois PH. Toronto tap water: perception of its quality and use of alternatives. Can J Public Health. 1992; 84(2): 99-102. PMID: 8334617.

10) Johnson BB. Do reports on drinking water quality affect customers' concerns? Experiments in report content. Risk Anal. 2003; 23(5): 985-98. doi: 10.1111/1539-6924.00375. PMID: 12969413.

11) de França Doria M. Factors influencing public perception of drinking water quality. Water policy. 2010; 12(1): 1-19. doi: 10.2166/wp.2009.051. PMID: 26223687, PMCID: PMC4520261.

12) Karnani A. The Mirage of Marketing to the Bottom of the Pyramid. California Management Review. 2007; 49(4): 90-111. doi: 10.2307/41166407.

13) Keramati H, Mahvi AH, Abdulnezhad L. The survey of physical and chemical quality of Gonabad drinking water in spring and summer of 1386. The Horizon of Medical Sciences. 2007; 13(3): 25-32.

14) Dupont D, Adamowicz WL, Krupnick A. Differences in water consumption choices in Canada: the role of socio-demographics, experiences, and perceptions of health risks. J Water Health. 2010; 8(4): 671-86. doi: 10.2166/wh.2010.143. PMID: 20705979. 
15) Doria M. Bottled water versus tap water: understanding consumers-preferences. J water health. 2006; 271 : 276.

16) Figueroa ME, Kincaid DL. Social, cultural and behavioral correlates of household water treatment and storage. Household water treatment and safe storage Geneva: World Health Organization. 2007.

17) Beamer PI, Luik CE, Abrell L, Campos S, Martínez ME, Sáez AE. Concentration of trichloroethylene in breast milk and household water from Nogales, Arizona. Environ Sci Technol. 2012; 46(16): 9055-61. doi: 10.1021/es301380d. PMID: 22827160, PMCID: PMC3699401.

18) Castleden H, Crooks VA, van Meerveld I. Examining the public health implications of drinking water related behaviours and perceptions: A face - to - face exploratory survey of residents in eight coastal communities in British Columbia and Nova Scotia. The Canadian Geographer/Le Géographe canadien. 2015. doi: 10.1111/cag.12169.

19) Dupont DP, Jahan N. Defensive spending on tap water substitutes: the value of reducing perceived health risks. Journal of water and health. 2012; 10(1): 56-68. doi: 10.2166/wh.2011.097. PMID: 22361702.

20) Victory KR. Risk Perception, Drinking Water Source and Quality in a Low-Income Latino Community along the US-Mexico Border. 2014.

21) Fattahi S, Alipourfard S, Habibi H. Analysis of determinants of mineral water consumption: the case of Tehran. Rev Contem Bus Res. 2013; 2(1): 41-55.

22) Edris B, Hamed B, Kord Mostafapour F. Determination of hydrophobic and hydrophilic fractions of natural organic matter in raw water of Zahedan water treatment plant. Health Scope. 2012; 1(1): 25-8.

23) Bazrafshan E, Biglari H, Kord Mostafapour F. Humic acid removal from aqueous environments by electrocoagulation process using iron electrodes. Journal of Chemistry. 2011; 3(1): 36-46. doi: $10.1155 / 2012 / 876739$.

24) Biglari H, Jonidi Jafari A, Kord Mostafapour F, Bazafshan E. Removal of Dissolved Organic Carbon from aqueous solution by Fenton Oxidation Process. Journal of Birjand University of Medical Sciences. 2012; 19(1): 70-80.

25) Sajjadi A, Afsharnia M, Azrah K, Sargolzai Javan N, Biglari H. Humic Acid Degradation via Solar PhotoFenton Process in Aqueous Environment. Iranian Journal of Health, Safety and Environment. 2015; 2(3): $304-12$.

26) Bazrafshan E, Joneidi Jaafari A, Kord Mostafapour F, Biglari H. Humic acid removal from aqueous environments by electrocoagulation process duad with adding hydrogen peroxide. Iranian Journal of Health and Environment. 2012; 5(2): 211-24.

27) Van der Bruggen B, Goossens H, Everard P, Stemgee K, Rogge W. Cost-benefit analysis of central softening for production of drinking water. J Environ Manage. 2009; 91(2): 541-9. doi: 10.1016/j.jenvman.2009.09.024. PMID: 19837505.

28) Shams M, Mohamadi A, Sajadi A. Evaluation of corrosion and scaling potential of water in rural water supply distribution networks of Tabas, Iran. World Appl Sci J. 2012; 17(11): 1484-89. 